\title{
O currículo e sua relação com o ensino de História: uma articulação necessária
}

lete Rodrigues Reis*

Marli Amélia Lucas Pereira**

\begin{abstract}
*Mestranda em Educação pela Faculdade de Educação da Universidade de São Paulo (Feusp) e professora de Metodologia do Ensino de História nas Faculdades Atibaia (Faat)
\end{abstract}

E-mail: ietereis@yahoo.com.br

**Doutoranda em Educação pela PUC-SP, coordenadora e docente no curso de Pedagogia da Faat, coordenadora e docente no curso de pós-graduação lato sensu em Metodologia de Ensino nos Anos Iniciais do Ensino Fundamental na Faat

E-mail:marlilucas1@gmail.com
Resumo: 0 presente artigo resulta de uma experiência em formação continuada para professores das séries iniciais do ensino fundamental ( $1^{0}$ ao $5^{\circ}$ ano). 0 curso ministrado tinha como objetivos, dentre outros, oferecer estudos de aprofundamento e atualização na temática de currículo e subsidiar inovações na prática pedagógica em sala de aula. Busca-se também evidenciar a pertinência e a atualidade da articulação de conhecimentos teóricos com a prática docente com vistas não apenas a melhorar a formação dos professores, mas também a auxiliá-los na complexa tarefa de ensinar crianças pequenas, contribuindo assim para o desenvolvimento do processo ensino/aprendizagem.

Palavras-chave: Formação continuada. Currículo. Metodologia. Prática docente. 
Quizás se podria decir que nunca estuvimos preparados para trabajar em estas realidades... Ni em éstas ni em aquellas. Estar preparado para el presente es siempre uma dificultad. Porque el presente o bien no dura o es inasible. Estar preparado para el futuro es astrologia y para el pasado, tango. La expresión "a mi nadie me preparó para esto", examinada más metódicamente, puede ayudar? Por qué?; porque quizás esse "esto" para

lo que se dice no estar preparado designe el núcleo duro de toda educación. (ANTELO, Estanislao. La Educación em Nuestras Manos, n. 72, oct. 2004)

O presente artigo é a apresentação do nosso trabalho como professoras das disciplinas Currículo e Conhecimento Escolar, e Conteúdos e Métodos do Ensino de História no curso de pós-graduação lato sensu da Faat - Faculdades Atibaia.

O curso de pós-graduação lato sensu Metodologia de Ensino nos Anos Iniciais do Ensino Fundamental foi elaborado a pedido da Secretaria de Educação do município de Atibaia para colaborar com a educação continuada dos professores dessa rede municipal. 0 curso tem por objetivos oferecer estudos de aprofundamento e capacitação profissional; proporcionar atualização, aprimoramento e aprofundamento de conhecimentos em currículo escolar, planejamento e avaliação, e conteúdos e métodos de ensino em Língua Portuguesa, Matemática, Ciências, História e Geografia; melhorar a capacitação dos professores para transmitir conhecimentos escolares específicos, manusear material didático, lidar com situações adversas à aprendizagem, incentivar e motivar o aluno para aprimorar sua capacitação pedagógica, desenvolver ações de nivelamento escolar, porque

Es que cada uno de los nuevos que viene al mundo actualiza la pregunta sobre el ser y sobre el enorme esfuerzo que llamamos educar. Em esse sentido para mi, no hay uma educación em la cual uno este al fin preparado para enfrentarse al enigma que le plantea cada nacimento [....] Si educar es operar sobre el outro com el propósito de hacer del outro um semejante, em realidad se podria decir que nadie está preparado [....] (ANTELO, 2004).

A disciplina Currículo e Conhecimento Escolar discute aspectos que dizem respeito às concepções de currículo e seus fundamentos, a visão de ciência na organização curricular e também a organização do conhecimento na escola. Tem por objetivos contextualizar e discutir as diferentes concepções de currículo na escola, e apresentar algumas abordagens contemporâneas sobre currículo, como interdisciplinaridade e currículo em rede.

A disciplina Conteúdos e Métodos do Ensino de História traz reflexões sobre o estado atual do ensino de História no ensino fundamental através do estudo da história e da historiografia do ensino de História no Brasil, proporcionando 
o entendimento dos fundamentos e conceitos da prática de ensino de História. Tem por objetivos identificar as condições atuais do ensino de História no Brasil no ensino fundamental, os desafios, as tensões e o papel do professor, especialmente na rede pública do ensino fundamental; compreender o processo histórico de formação do ensino de História: a organização curricular, os conteúdos e práticas, os materiais de ensino sobretudo o livro didático; analisar os fundamentos e conceitos do ensino de História a partir de uma abordagem histórica dos conteúdos e métodos do ensino de História; e refletir sobre os materiais e métodos do ensino de História, abordando uma variedade de suportes e linguagens, como livros didáticos, vídeos, fotografias, jornais , internet e estudos de meio.

Entendemos que as discussões a respeito de currículo e ensino de História trazem benefícios para o desenvolvimento profissional do professor. Imbernón (2006), ao discutir sobre a profissão docente, leva em consideração que existe a necessidade de estudar as novas competências que o professor adquire na sociedade atual, fazer com que a profissão docente seja mais atrativa e potencializar uma instituição educativa mais autônoma, com responsabilidade por sua gestão pedagógica.

De acordo com Imbernón (2006),

\section{[...] que la profesión docente há adquirido uma gran complelidad em esta sociedad del conocimiento, que há aumentado la diversidad de usuários [...], que hay más problemas de aprendizaje y disciplina, de heterogeneidad, que em muchos países se há escolarizado a toda la poblacion em los últimos años a traves de uma ensenãnza masiva [...] (p.42).}

Na visão de André (2010), o desenvolvimento profissional é um processo de longo prazo, tem caráter intencional e leva em consideração a importância do planejamento das atividades e experiências que possam promover esse desenvolvimento. Nesses processo, é preciso dar a devida atenção às representações, crenças e preconceitos dos docentes, porque podem afetar sua aprendizagem da docência e assim possibilitar ou dificultar as mudanças.

Deve-se compreender que quando tratamos de desenvolvimento profissional, olhamos para o professor que está atuando na escola e, nesse sentido, levamos em consideração a dimensão coletiva e institucional, incluindo equipes de gestão, pessoal não docente e o próprio professor.

Quando falamos de desenvolvimento profissional, estamos reconhecendo o caráter específico do professorado e a existência de um espaço onde é exercida a profissão. Reconhecemos que os professores podem serverdadeiros agentes 
sociais, planejadores e gestores do processo de ensino/aprendizagem, e que podem intervir nos complexos sistemas que fazem parte da estrutura social e de trabalho.

Ao pensarmos a respeito de uma nova formação, de um novo desenvolvimento profissional, entendemos como Imbernón que

[...] debe proponer um proceso de formación que capacite AL profesorado em conocimientos, destrezas y actitudes para deserrollar profesinales reflexivos o investigadores (...) y cuya meta es aprender a interpretar, compreender y reflexionar sobre la ensenânza y la realidad socil de forma comunitária. Adquiere relevância también el carácter ético de la actividad educativa (IMBERNÓN, 2009, p. 38-39).

É preciso favorecer debates e a construção de bases reais para construir projetos de ligação entre a instituição formadora e a escola. A melhoria da formação e do desenvolvimento profissional do professor está em estabelecer caminhos para conquistar melhoras pedagógicas, além de um debate entre 0 próprio coletivo de professores.

Levando em conta as considerações acima apresentadas, o objetivo é apresentar como desenvolvemos nosso trabalho nas disciplinas Currículo e Conhecimento Escolar, e Conteúdos e Métodos do Ensino de História.

\section{A disciplina Currículo e ConheCimento Escolar}

Como docentes no ensino superior em cursos de licenciatura, acreditamos que compreender o significado de currículo implica um posicionamento do futuro professor a respeito da sua atuação na escola básica e, nesse sentido, na compreensão da organização dos conteúdos na sala de aula. Zabala (1998) entende que nas atividades e tarefas que definem a prática na aula, trabalham-se conteúdos de aprendizagens distintos e, habitualmente, mais de um conteúdo. Para o referido autor, "as relações e a forma de vincular os diferentes conteúdos de aprendizagem que formam as unidades didáticas é o que denominamos organização dos conteúdos” (ZABALA, 1998, p. 139).

Principalmente a partir do final da década de 1980 são recorrentes as discussões a respeito de currículo no Brasil. De acordo com o artigo 210 da Constituição Federal de 1998, que determina como dever do Estado para com a educação fixar "conteúdos mínimos para o ensino fundamental, de maneira a assegurar a formação básica e comum e respeito aos valores culturais e artísticos, nacionais e regionais”, o MEC (Ministério da Educação e Cultura) elaborou, a partir de 1995, os Referenciais Curriculares Nacionais para a 
Educação Infantil (RCNEI) e os Parâmetros Curriculares Nacionais (PCN).

No ano de 2008, o Ministério da Educação, por meio da Secretaria da Educação Básica, publicou um documento denominado Indagações sobre currículo que tem como perspectiva atender aos desafios e normas vigentes por meio de discussões a respeito de concepções de currículo. Esse documento prioriza discussões a respeito das relações entre currículo e desenvolvimento humano; currículo e o direito de educadores e educandos; currículo, conhecimento e cultura; diversidade e currículo; e currículo e avaliação.

De acordo com o documento Indagações sobre currículo, na Introdução (2008, p. 9):

As indagações sobre o currículo presentes nas escolas e na teoria pedagógica mostram um primeiro significado: a consciência de que os currículos não são conteúdos prontos a serem passados aos alunos. São uma construção e seleção de conhecimentos e práticas produzidos em contextos concretos e em dinâmicas sociais, políticas e culturais, intelectuais e pedagógicas. Conhecimentos e práticas expostos às novas dinâmicas e reinterpretados em cada contexto histórico [...].

Entendemos que as questões sobre currículo estão privilegiadas nos projetos político-pedagógicos das escolas e nas propostas dos sistemas de ensino, bem como em discussões realizadas no processo de formação inicial de professores. Nessa perspectiva, é possível entender que a proposta desse documento vai em direção à reflexão, à busca de significados na perspectiva de reorientação do currículo e de práticas educativas.

Sacristán e Gómez (1998, p. 125) explicam que “o termo currículo provém da palavra latina currere, que se refere a carreira, a um percurso que deve ser realizado". Podemos entender que a escolaridade é um percurso para os alunos e o currículo o guia para a escolaridade, e nesse sentido compreendemos que a concepção de currículo não pode estar desligada do contexto no qual se elabora e que não existe uma única concepção. De acordo com Sacristán e Gómez (1998), para entender a multiplicidade de significados é preciso entender quatro dimensões relacionadas ao conceito de currículo.

Na primeira dimensão indicada por Sacristán e Gómez (1998), “amplitude variável do significado", o conceito de currículo é elástico porque pode significar coisas distintas e isso implica compreender as possibilidades de perspectivas diferentes sobre a realidade de ensino. A segunda dimensão, "o currículo dentro de práticas diversas", demonstra que a escola, por meio do ensino, pode transmitir uma dada cultura que faz parte do seu contexto. A terceira dimensão, "o oculto e o manifesto: uma visão dos que aprendem", aponta que a realidade não se reduz ao que parece evidente, mas é preciso 
descobrir o que não está evidente. Isso significa explicitar as intenções do processo de ensino/aprendizagem. Finalmente, a quarta dimensão, "dos propósitos das ideias e prática do currículo", sinaliza que o currículo é um campo privilegiado para apreciar algumas contradições, como a separação entre intenções e prática. Os autores explicam que para conhecer o currículo é importante ir além das declarações, da retórica, de documentos, ou seja, ficar mais próximo da realidade.

Goodson (2008), ao realizar uma análise sobre as políticas de currículo e a escolarização, focou a discussão na compreensão sobre a seleção cultural dos conteúdos ensinados e aprendidos nas salas de aula, o que incentivava a reflexão, a definição e a hierarquização dos conteúdos no processo de escolarização.

Nas palavras do autor:

Ao invés de escrever novas prescrições para as escolas, novos currículos ou novas diretrizes de reforma, elas precisam antes questionar a própria validade das prescrições [...]. Precisamos sair do currículo como prescrição para o currículo como narração de identidade, do ensino cognitivo prescrito para o ensino narrativo do gerenciamento da vida (GOODSON, 2008, p. 142).

Zabala (1998), ao tratar da organização dos conteúdos na escola, entende que nos modelos disciplinares a concepção de como se aprende, no que se refere à organização dos conteúdos, tem importância relativa, uma vez que o fator fundamental está no papel que se atribui ao ensino, ou seja, sua função social (que tipo de cidadão se propõe, que capacidades é preciso desenvolver). Para o autor,

\begin{abstract}
[...] o debate não consiste em seguir ao pé da letra um método [...] ou se inclinar por um modelo disciplinar [...] a resposta será a opção de organizar os conteúdos a fim de nos assegurar ao máximo [...] de que as aprendizagens sejam as mais significativas possiveis para que os meninos e meninas aprendam e lhes ajude a se formar como cidadãos competentes para compreender a sociedade em que vivem e participar nela construtivamente (ZABALA, 1998, p. 165).
\end{abstract}

Levamos em consideração, no decorrer da disciplina Currículo e Conhecimento Escolar, discussões estabelecidas nos documentos e autores referenciados acima. No desenvolvimento da disciplina introduzimos atividades de reflexão a respeito do significado de currículo oportunizadas por dinâmicas que possibilitaram aos professores em formação apresentar sua concepção de currículo. Trabalhamos na tentativa de articular o significado de currículo com a prática pedagógica na sala de aula.

O tema diversidade e currículo foi o desencadeador de nossas discussões e permeou todo o trabalho realizado na disciplina. Para Moreira e Candau (2008), a sociedade é construída em contextos históricos, socioeconômicos 
e políticos tensos, marcados por processos de colonização e dominação. Trabalhar com a diversidade na escola significa construir práticas que expressem a riqueza das identidades e da diversidade cultural presente na escola e na sociedade. Dessa forma, poderemos avançar na superação de concepções românticas sobre a diversidade cultural presentes nas práticas e nos currículos.

Essa concepção foi a marca do nosso trabalho com a disciplina Currículo e Conhecimento Escolar. Entendemos que assumir um trabalho que leva em consideração a diversidade é posicionar-se contra as diversas formas de dominação, exclusão e discriminação.

\section{A disciplina Conteúdos e Metodologia do Ensino de História}

Ensinar História nas séries iniciais do ensino fundamental tem sido um desafio permanente para os professores. Esse desafio pode ser analisado pelo menos por dois aspectos. 0 primeiro diz respeito à formação inicial do professor que tradicionalmente atua nas séries iniciais. Para ingresso na carreira de professor das séries iniciais, é exigida a formação em Pedagogia ou curso normal superior. Esta formação é genérica e o professor é polivalente, isto é, ministra todas as disciplinas do núcleo comum, previstas na Lei 9496/96, a Lei de Diretrizes e Bases da Educação Nacional.

O segundo refere-se ao predomínio nas séries iniciais do ensino de Língua Portuguesa e Matemática. Na maioria das escolas públicas, do total das 25 horas/aula semanais, apenas duas são destinadas à disciplina História. A própria "grade curricular" - a palavra grade utilizada de forma corrente não é aleatória - simboliza a burocratização da escola pública, onde o trabalho pedagógico é segmentado em funções e disciplinas específicas, diferenciadas em termos de competências e habilidades. O professor, diante da necessidade de atenderà organização burocrática do currículo, tem seu trabalho engessado. Além disso, as avaliações externas nas séries iniciais focam a aprendizagem das habilidades em Língua Portuguesa. Nesse sentido, o desenvolvimento curricular com abordagem de diferentes conteúdos e métodos específicos de cada disciplina, em vez da necessária articulação entre elas, é feito de forma segmentada, prejudicando o ensino, a aprendizagem e a avaliação, tendo como consequência o empobrecimento do currículo escolar e das práticas docentes na sala de aula. 
Se concordarmos que a escola pública é o único espaço organizado, relativamente estável, que permite o primeiro contato das crianças com a realidade da cultura e do mundo adulto, um espaço que permite o desenvolvimento da sociabilidade e da percepção do coletivo, além do ambiente familiar, é certo afirmar que a escola é o locus inicial e privilegiado do processo de construção da cidadania. Este, quando bem conduzido, permite a vivência e o posterior desenvolvimento de possível reflexão sobre a realidade social e política do país.

Desse ponto de vista, a escola e o currículo têm papel fundamental na formação da identidade de cada pessoa. A escola, conforme lembra Bittencourt (2004), integra um conjunto de objetivos determinados pela sociedade e articula-se com eles, contribuindo para os diferentes processos econômicos e políticos. O currículo escolar, portanto, é prenhe de intencionalidade e seus objetivos estão inseridos em cada uma das disciplinas. Estas fazem parte de uma teia complexa na qual a escola desempenha o papel de fornecedora de "conteúdos de instrução", que além dos objetivos de formação intelectual, da aquisição de "habilidades e atitudes", obedecem a objetivos educacionais definidos mais amplos (BITTENCOURT, 2004, p. 42).

À complexidade dos objetivos educacionais, da estrutura organizacional da escola e à forma como o currículo é desenvolvido, outro problema no ensino de História nas séries iniciais merece reflexão: a tradição do ensino de História, com forte viés positivista, ainda está presente no cotidiano da sala de aula. Aqui vale ressaltar que o ensino de História foi veiculado nas escolas com diferentes intencionalidades, que incluem a necessidade de formação de uma identidade nacional nas décadas finais do século XIX e a necessidade de inclusão social de imigrantes europeus e negros libertos, com vistas à formação moral, ao disciplinamento, à obediência às regras e à manutenção da ordem de modo que a nação chegasse ao progresso nos moldes europeus.

Nas primeiras décadas do século XX, o ensino de História se propõe a inculcar o patriotismo. Para tanto, os conteúdos básicos narravam a riqueza e as belezas naturais, a boa gente mestiça, risonha e cordial. Os anos de 1930 marcaram a consolidação de uma memória histórica nacional e patriótica. 0 ensino de Língua Portuguesa, História do Brasil, Educação Moral e Cívica e Geografia do Brasil constituíram o núcleo central do currículo para a formação nacionalista e patriótica, e na prática sedimentaram o culto aos heróis, aos símbolos nacionais - com destaque ao Hino Nacional e à Bandeira - e aos poemas nacionalistas, até hoje presentes nas aulas e festas cívicas. Sobre esse assunto, Marcus Vinícius de Morais se posiciona da seguinte maneira: 
É importante refletir e ser realista: as pessoas em geral terão o seu conhecimento histórico, até o fim de suas vidas, formado pelo que aprendem na escola e nos livros a que têm acesso durante sua infância e adolescência, quando são estudantes. $O$ conteúdo escolar, normalmente, é o principal responsável pela noção de história que os indivíduos possuem, pois raras vezes os repertórios pessoais de conhecimento sobre o passado serão acrescidos posteriormente. Dificilmente os conteúdos serão revisitados (MORAIS, 2010, p. 202).

Esse mesmo autor ressalta a grande responsabilidade de ser professor de História, pois, aliado ao fato do currículo, em certos momentos estar a serviço dos interesses do Estado, com vistas a propagar as imagens que mais interessavam ao projeto deste, como já foi apontado, o trabalho em sala de aula lida com as imagens que os alunos têm de si mesmos, de suas comunidades, de seu país e do mundo em que vivem. Por outro lado, o trabalho docente torna-se ainda mais complexo com o fator já citado, a insuficiente formação inicial dos docentes das séries iniciais. Os cursos de Pedagogia, em geral, não abordam as especificidades da disciplina História, entre elas o necessário entendimento de que o currículo e os conteúdos de História são narrativas historicamente construídas, pois, concordando mais uma vez com Morais,

\section{[...] o que os povos dizem sobre o seu passado nos revela como gostam de ser lembrados e muito do próprio momento em que nasce a narrativa. Podemos lembrar e dizer coisas a respeito do passado, mas os motivos, as emoções e os porquês se localizam sempre no momento atual em que as versões da narrativa histórica são criadas e transmitidas (MORAIS, 2010, p. 201).}

Na sequência temporal, os rumos políticos da história do Brasil, que intercala curtos períodos de democracia com períodos de autoritarismo, como o Estado Novo e a ditadura militar, o currículo escolar e principalmente o currículo de História têm variado conforme as necessidades do projeto do Estado. Nesses períodos de exceção, o livro didático torna-se portador de verdades inquestionáveis, passam a dominar a cena na sala de aula e os professores ficam enjaulados nos "cárceres pedagógicos", criados pelo Estado. As narrativas contadas e recontadas pelos professores acabam se tornando verdades didáticas estanques e inabaláveis, como dogmas de explicação histórica (MORAIS, 2010, p. 201-205).

A educação escolar toma novos rumos nas décadas de 1980 e 1990. O soprar dos ventos da democracia inspira debates e acirra a disputa pelo currículo, os confrontos com professores, imprensa, órgãos do governo e acadêmicos envolvem polêmicas, negações ou rejeições das propostas para o ensino de História, construídas entre os anos de 1986 e 1992 (MARTINS, 1996). A Constituição Federal, promulgada em 1988, colocou a centralidade do Estado de direito, enfatizando o direito subjetivo à educação de todos os brasileiros. 
Diante dessa nova ordem democrática, depois de tramitar por dez anos, foi finalmente sancionada a Lei de Diretrizes e Bases - Lei 9496/96. Nesse contexto, em 1997 foram editados os Parâmetros Curriculares Nacionais PCNs, que destacam o respeito às diferenças e a valorização da diversidade e pluralidade culturais como patrimônios do Brasil.

Diante desse novo quadro sociopolítico e das então recentes regulamentações da educação, a escola, sua gestão e currículo também passam por revisão. Novos temas surgem nesse contexto: a elaboração de novas propostas curriculares, a gestão democrática da escola, a construção coletiva do projeto político-pedagógico, a participação da comunidade, conselhos escolares, entre outros, passam a fazer parte do cotidiano dos educadores.

Acompanhando esse movimento, o currículo de História para a educação básica passa a ser pensado e desenvolvido com abordagens inspiradas em uma nova historiografia, sobretudo as tendências da história cultural. Por sua vez, os livros didáticos, como decorrência desse novo enfoque, passam a trazer elementos da história nova, da história das mentalidades, do multiculturalismo. Surgem novos objetos, novas personagens, privilegia-se o estudo das características de determinados grupos sociais, as comunidades locais, a classe trabalhadora, os vencidos - como indígenas, quilombolas, entre outros -, em detrimento da história nacional, vista como arcaica e ultrapassada (MORAIS, 2010, p. 205).

Por seu turno, essas mudanças no currículo trazem desafios urgentes para os professores, que precisam criar novas práticas pedagógicas, ou seja, uma nova didática para novos conteúdos, com novos objetivos. Circe Bittencourt traz a seguinte contribuição:

As mudanças no ensino de disciplina com consolidada tradição na vida escolar, como acontece no caso da História, constituem sempre tarefa complexa. A tradição escolar é compartilhada pela comunidade escolar, incluindo as famílias, e não apenas pelos professores. $O$ desejo de mudanças para melhor desempenhar o trabalho com os alunos tem estado presente na história da prática docente, mas é preciso entender que métodos e conteúdos se constroem historicamente e fazem parte de uma produção escolar sedimentada e incorporada pela sociedade (BITTENCOURT, 2004, p. 229).

Nessa necessidade de novas práticas, posto que acrescida à notória complexidade do ensino de História, tradicionalmente destinado ao antigo ensino secundário (ginásio), a História passa a ser disciplina obrigatória já nos anos iniciais de escolarização. Surgem novos desafios, como ensinar História 
para crianças pequenas e o que ensinar. Quais suportes utilizar com crianças ainda não alfabetizadas? Essa problemática norteou todo o desenvolvimento do curso de Metodologia de Ensino de História para os anos iniciais, já que na visão de Abud e Zamboni (1992), o aprofundamento sobre o ensino de História é fruto de reflexões conjuntas realizadas nos campos da teoria e da prática docente. Se o antigo método de memorização, que consistia em saber de cor nomes, fatos e datas, repetindo o que estava escrito no livro ou copiado nos cadernos, presente no imaginário da maioria dos professores estava ultrapassado e não cabia na lida com crianças pequenas, o que fazer? Dar resposta a essas indagações foi o nosso desafio.

\section{CONSIDERAÇÕES FINAIS}

Ao tratar do currículo e sua articulação com o ensino de História, entendemos que isso propicia uma rica reflexão por parte dos professores formadores e por parte dos professores que atuam na rede pública municipal, como foi o caso deste artigo. Nosso trabalho envolveu uma parceria estabelecida entre a Secretaria Municipal de Educação e nossa faculdade, as Faculdades Atibaia - Faat.

Buscamos o apoio de Canário (2001), uma vez que entende que devemos levar em conta a prática na formação profissional de professores. Compreende que as discussões devem ter um olhar aguçado para o currículo como espaço de revalorização da experiência profissional. Enuncia três grandes orientações “[...] que podem servir de referência para a tradução em termos curriculares de revalorização da experiência [...]” (p. 41). Essas três orientações nos ajudam a ampliar, organizar e estruturar o currículo.

A primeira orientação apontada por Canário (2001) amplia o conceito de currículo e se refere à necessidade "[...] de construir outra inserção espacial das atividades de formação [...]” (p. 41) e que deve ser olhada por dupla perspectiva: 1) evoluir de espaço tradicional para espaço educativo, que faz com que se encare a escola de formação inicial como espaço que engloba tudo o que acontece no quadro da instituição escolar; e 2) a relação interativa entre escolas e outros espaços sociais consiste na aproximação com os contextos reais do exercício profissional. Isso deve estar presente ao longo de todo o percurso de formação inicial.

A segunda orientação que nos leva a refletir sobre a organização do currículo tem a preocupação “[...] de, sistematicamente, multiplicar as ocasiões de 
dar a palavra aos alunos, e à expressão das suas vivências e expectativas" (CANÁRIO, 2001, p. 42). Aqui Canário chama a atenção para a atitude de escuta na tentativa "[...] de levar em conta os saberes tácitos dos formandos, construídos de modo intuitivo na ação cotidiana [...]” (p. 42).

A terceira orientação que nos leva a refletir sobre estruturar o currículo consiste na “[...] articulação interativa entre situações de informação, situações de interação e situações de produção [...]" (CANÁRIO, 2001, p. 42). Essa orientação indica que, ao olharmos para a estruturação do currículo, devemos levar em conta a produção de saberes e compreender que o formando seja sujeito e agente de transformação. Quando o formando é considerado ao mesmo tempo aprendiz e agente socializador, ele contribui, como afirma Canário (2000),

[...] Para mudar representações e comportamentos dos profissionais já "veteranos". Esta capacidade de questionar criticamente as práticas de profissionais experimentados, aprendendo com elas e contra elas, só é possível se, dentro da escola de formação inicial, os alunos forem tratados como produtores de saberes ( $p .42)$.

A prática profissional como elemento estruturante do processo formativo é entendida como uma situação interativa “[...] que envolve de forma simultânea os alunos, os profissionais no terreno e os formadores" (CANÁRIO, 1998, p. 24; 2001, p. 44). A prática profissional é sempre um processo. Em primeiro lugar, é o principal elo à realidade do contexto; em segundo lugar, leva em consideração os estabelecimentos de ensino, a escola como um todo e não apenas os professores "cooperantes"; em terceiro lugar, que se estruture a partir de um eixo metodológico que tenha como referenciais as situações de trabalho.

É possível compreender que nesse texto publicado em 2001, Canário avança ao levar em conta o currículo como elemento estruturante da revalorização da experiência na formação de professores, que significa "[...] aprender a aprender com a experiência [...]" (p. 44), que a experiência no processo de formação não significa subestimar a teoria. Canário (2001) entende o professor como um analista simbólico "[...] a quem compete equacionar e "construir" problemas, no terreno da prática, marcada pela incerteza e a complexidade, e não a dar respostas previamente aprendidas para situações inteiramente previsíveis" (p. 44).

É preciso analisar os cursos de formação continuada olhando para a prática profissional com foco na capacidade de que essas escolas de formação cumpram com zelo sua tarefa. Na tentativa de articular os conhecimentos 
do ensino de História com discussões estabelecidas pela área de currículo com os estudantes da turma de 2012, compreendemos que levamos em consideração a prática profissional e os saberes dos professores matriculados nas disciplinas e no curso de pós-graduação lato sensu Metodologia de Ensino dos Anos Iniciais do Ensino Fundamental. 


\section{Curriculum and its relationship with History teaching: a necessary connection}

Abstract: The present article is the outcome of an experiment in continued education for teachers of elementary education early series ( $1^{\circ}$ to $5^{\circ}$ grade). The course's purposes were, among others, to provide studies aimed at deepening and updating curriculum topic and give support to innovations in pedagogical practices in the classroom. There is also the concern to make clear the relevance and topicality of connecting theoretic knowledge to teaching practice aiming at not only to improve teachers' upbringing but also help them with the complex task of teaching to young children, therefore adding to the development of the teaching/learning process.

Keywords: Continued education. Curriculum. Methodology. Teaching practice. 


\section{REFERÊNCIAS}

ABUD, K. M.; ZAMBONI, Ernesta. Proposta Curricular par o Ensino de História (1ํgrau) do Estado de São Paulo. São Paulo: Secretaria da Educação do Estado de São Paulo - CENP; Imprensa Oficial, 1992 (Introdução).

ANDRÉ, M. Formação de professores: a constituição de um campo de estudos. Educação, Porto Alegre, v. 33, n. 3, p. 14-181, set./dez. 2010.

ANTELO, E. La Educación en Nuestras Manos, n.72, out. 2004.

BITTENCOURT, C. M. F. Ensino de história: fundamentos e métodos. São Paulo: Cortez, 2004.

CANÁRIO, R. A prática profissional na formação de professores. In: CAMPOS, Bartolo Paiva (Org.). Formação profissional de professores no ensino superior. Porto: Afrontamento, 2001.

GOODSON, I. F. As políticas de currículo e de escolarização. Petrópolis: Vozes, 2008.

GOVERNO DO ESTADO DE SÃO PAULO. Secretaria de Educação. Série Ideias, FDE, n. 16, 1993.

IMBERNÓN, F. La profesión docente desde el punto de vista internacional. Que dicen los informes? Revista de Educación, n. 340, p. 19-86, maio-ago. 2006.

Una nueva formación permanente del profesorado para um nuevo desarrollo professional y coletivo. Revista Brasileira de Formação de Professores- RBFP, v. 1, n. 1, p. 31-42, maio 2009.

MARTINS, M. C. A construção da proposta curricular de história da Cenp no período de 1986 a 1992: Confrontos e conflitos. Campinas, 1996. Dissertação (Mestrado em Educação) - Faculdade de Educação, Universidade Estadual de Campinas.

MORAIS, M. V. História integrada. In: PINSKY, Carla B. (Org.). Novos temas nas aulas de história. São Paulo: Contexto, 2010, p. 201-218.

MOREIRA, A. F. B.; CANDAU, V. M. Indagações sobre currículo: currículo, conhecimento e cultura. Brasília: Ministério da Educação, Secretaria de Educação Básica, 2008.

SACRISTÁN, J. O currículo: uma reflexão sobre a prática. Porto Alegre: Artmed, 1998. 
; GÓMEZ, A. I. Pérez. Compreender e transformar o ensino. Porto Alegre: Artmed, 1998.

SÃO PAULO (Estado). Secretaria da educação. Coordenadoria de Estudos e Normas Pedagógicas. Proposta curricular para o ensino de história: primeiro grau. São Paulo: SE/Cenp, 1992.

ZABALA, A. A prática educativa: como ensinar. Porto Alegre: Artes Médicas, 1998.

RECEBIDO: Janeiro de 2014.

APROVADO: Março de 2014. 